\title{
Correction to: The non-lane-discipline-based car-following model considering forward and backward vehicle information under connected environment
}

\author{
Jiacheng Xiao $\cdot$ Minghui Ma $(\mathbb{C} \cdot$ Shidong Liang $\cdot$ Guangyi Ma
}

Published online: 7 December 2021

(C) Springer Nature B.V. 2021

\section{Correction to: Nonlinear Dyn}

https://doi.org/10.1007/s11071-021-06999-8

The original article was published with formula, equation and textual errors. Listed and noted below are the errors and the intended information.

Figure correction:

\begin{tabular}{lll}
\hline Location & Error & Correction \\
\hline Fig.5 & $\begin{array}{l}\text { Each of the subgraphs in } \\
\text { Figure 5 lack of explanatory } \\
\text { coefficients }\end{array}$ & $\begin{array}{c}\text { (a) } p=1 \\
\text { (b) } p=0.95\end{array}$ \\
& & (c) $p=0.9$ \\
& & (d) $p=0.85$ \\
Fig.6 & $\begin{array}{l}\text { Each of the subgraphs in } \\
\text { Figure 6 lack of explanatory } \\
\text { coefficients }\end{array}$ & (a) $p=1$ \\
& (b) $p=0.95$
\end{tabular}

The original article can be found online at https:// doi.org/10.1007/s11071-021-06999-8.

J. Xiao · M. Ma $(\bowtie) \cdot$ G. Ma

School of Mechanical and Automotive Engineering,

Shanghai University of Engineering Science,

Shanghai 201620, China

e-mail: maminghui1989@hotmail.com

\section{S. Liang}

Business School, University of Shanghai for Science and

Technology, Shanghai 200 093, China

\begin{tabular}{lll}
\hline Location & Error & Correction \\
\hline & & $\begin{array}{l}\text { (c) } p=0.9 \\
\text { (d) } p=0.85\end{array}$ \\
Fig.7 & $\begin{array}{c}\text { Each of the subgraphs in } \\
\text { Figure 7 lack of explanation }\end{array}$ & $\begin{array}{l}\text { (a) FVD model } \\
\text { (b) NLBCF } \\
\text { model }\end{array}$
\end{tabular}

(c) BLVD model

Fig.8 Each of the subgraphs in Figure 8 lack of explanation

(a) FVD model

(b) NLBCF model

(c) BLVD model (d) NLFB model

Fig.9 Each of the subgraphs in Figure 9 lack of explanation

(a) FVD model (b) NLBCF model

(c) BLVD model (d) NLFB model

Describe correction: 


\begin{tabular}{lcc}
\hline Location & Error & Correction \\
\hline Section 2 (Model), & $V_{B}\left[\left(\Delta x_{n, n+1}(t)\right.\right.$, & $V_{B}\left[\left(\Delta x_{n, n-1}(t)\right.\right.$, \\
paragraph 5, line1. & $\left.\left.\Delta x_{n, n+2}(t)\right)\right]$ & $\left.\left.\Delta x_{n, n-2}(t)\right)\right]$ \\
Section 3 (Stability & with increasing & with increasing \\
analysis), the third & & parameter $p_{n}$ \\
paragraph from the & & \\
bottom, line2. & & \\
Section 3 (Stability & stability critical & critical \\
analysis), last & stability & sensitivity \\
paragraph, line2. & & \\
\hline
\end{tabular}

Publisher's Note Springer Nature remains neutral with regard to jurisdictional claims in published maps and institutional affiliations. 